\title{
Kriz ve Stres Sürecinde Liderlik Türleri Kurumsal Duygusal Zekâyı ve İnsan Kaynakları Motivasyonunu Nasıl Etkileyebilir?
}

\author{
DOI: $10.26466 /$ opus.809051
}

\author{
Ceylan Gazi Uçkun * - Hasan Latif ** - Okan Şeneldir *** \\ * Prof. Dr., Kocaeli Üniversitesi, Hereke Ö.İ Uzunyol MYO, Kocaeli/ İstanbul \\ E-Posta: guckun@gmail.com \\ ORCID: $0000-0002-0169-5401$ \\ ** Prof. Dr., Kocaeli Üniversitesi, Hereke Ö.İ Uzunyol MYO, Kocaeli/ Türkiye \\ E-Posta: haslat@gmail.com \\ ORCID: $0000-0002-7529-4950$ \\ *** Dr. Öğr. Üyesi, Kocaeli Üniversitesi, A. Rıza Veziroğlu MYO, Kocaeli/ Türkiye \\ E-Posta: seneldir@gmail.com \\ ORCID: $\underline{0000-0001-5464-7545}$
}

Öz

Günümüzde artan iletişim ve ulaşım teknolojilerindeki gelişmelerle birlikte krizler, Dünya çapında yaygınlaşmaya başlamıştır. Hızla değişen çevresel koşullara uyum gösterebilen kurumlar, stres ve kriz yönetiminde daha başarll olmuştur. Günümüzde önemi daha çok anlaşılan ve karar verici durumunda olan örgüt veya ülke liderleri; küresel ölçekte ön plana çıkmıştır. Ekonomik krizler, çalışanların ruh sağlığını olumsuz yönde etkileyen önemli bir stres nedeni olmuştur. Artan çevresel karmaşıklık ve örgütlerin değişen doğalarn nedenleriyle liderler, kriz sürecinde büyük zorluklarla karşılaşmıştır. Çalışanların motivasyon ve duygusal zekâ özellikleri, yöneticilerinin çabalarıyla gelişmiş ve böylece kurumların liderlik gücü artmıştır. Bu çalışmada liderlik türlerinin, kurumsal duygusal zekâ ve insan kaynakları motivasyonu ile ilişkisi incelenmiştir. Üstelik, bu tür ilişkilerin kriz ve stres sürecinden nasıl etkilendiği tartışılmıştır. Kurumsal duygusal zekâ ve insan kaynakları motivasyonu konularına odaklanan ender çalışmalardan birisi olması nedeniyle önem arz eden bir çalışmadır. Literatür taraması yöntemi kullanılan çalışmada; kriz ve stres kavramların açıklamak, kurumsal duygusal zekâ ve insan kaynakları motivasyonunun önemini sorgulamak ve liderlik türlerinin etkilerini açığa çıkarmak amaçlanmıştır. Çalışma, liderlik türleri arasında bulunan dönüştürücü ve ruhsal liderlerin, kriz ve stres sürecinde daha etkili oldukları görüşüyle sonuçlandırılmıştır.

Anahtar Kelimeler: Kriz, stres, liderlik, zekâ, motivasyon 


\title{
How Leadership Types Can Impact Corporate Emotional Intelligence and Human Resources Motivation in the Crisis and Stress Process?
}

\begin{abstract}
Crises have started to spread around the world with the developments in communication and transportation technologies. Institutions that can adapt to rapidly changing environmental conditions have been more successful in stress and crises management. Leaders of organizations or countries whose importance is understood more and who are decision makers today; has come to the fore on a global scale. Because of the increasing environmental complexity and the changing nature of organizations, leaders faced major challenges during the crisis. The motivational and emotional intelligence characteristics of the employees have been developed with the efforts of their managers and thus the leadership power of the institutions has increased. In this study, the relationship of leadership styles with corporate emotional intelligence and human resources motivation was examined. Moreover, it has been discussed how such relationships are affected by the crisis and stress process. It is an important study because it is one of the rare studies focusing on corporate emotional intelligence and human resources motivation. The study using the literature review method, concluded with the view that transformative and spiritual leaders, which are among the leadership types, are more effective in the crisis and stress process.
\end{abstract}

Keywords: Crisis, stress, leadership, intelligence, motivation. 


\section{Giriş}

Lider, diğer insanlar tarafından ileri görüşlülüğüyle örnek alınan ve bir öncü olarak kabul edilen bir insandır. Bulunduğu ortamda yaratıcılığın arttırılmasına ön ayak olan lider, insanlar arasındaki iletişimi geliştirir ve yürütülen işlerin tamamlanmasını sağlayacak motivasyonu destekler. Geleceğe yönelik başlangıçların nasıl yapılacağına ve işlerin nasıl yürütüleceğine yönelik bir rehber olan lider, işlerin aksatılmasına karşı sabır gösterilmesini sağlar (Bono ve Judge, 2004, s.903-905).

Hangi liderlik türlerinin, insan kaynaklarının motivasyonu ve kurumsal duygusal zekâ üzerinde daha etkili olduğunu belirlemek; araştırmanın problemi olarak belirlenmiştir. İnsan kaynaklarının motivasyonu ve kurumsal duygusal zekâ üzerinde, liderlik türlerinin etkilerinin farklı olup olmadığının belirlenmesi ise; araştırmanın amacıdır. Küresel ölçekte etkileri olan krizler, iletişim ve ulaşım teknolojilerindeki ilerlemelerle birlikte, yaygınlaşma hızını ve sıklığını artırmıştır. Yaygınlaşan krizlere son örnek olarak, 2020 yılında yaşanan pandemi süreci verilebilir. Pandemi sürecinin ekonomik durgunluğu ve daralmayı tetiklemesi ve bu nedenle, örgütlerde çalışan insan kaynaklarının duygusal zekâları üzerinde motivasyon kırıcı sonuçlara yol açması; çalışmanın gerekçesidir. Kriz sürecinde liderliğin etkilerini inceleyen çalışmalar literatürde mevcuttur. Bu çalışma ise, kurumsal duygusal zekâ ve insan kaynakları motivasyonu konularına odaklandığı için, ender çalışmalardan birisi olması nedeniyle önem arz etmektedir.

Literatür taraması yöntemi kullanılan çalışmada beş bölüm bulunmaktadır. Birinci bölüm kriz ve stres sürecini incelemiştir. İkinci bölümde kurumsal duygusal zekâ ve üçüncü bölümde ise insan kaynaklarının motivasyonu incelenmiştir. Dördüncü bölüm, liderlik türleri ve etkilerini incelemiştir.

\section{Kriz ve Stres Süreci}

Kriz sürecinde; kuruluşun hedeflerine yönelik tehditlere yönelik önlemler için gerekli zaman, yetersizdir. Bu nedenle krizler, liderlerin karar alma gücünü azaltarak yüksek düzeyde stres oluşturan ve normal sürecin dişında yer alan dönemlerdir (Canöz ve Öndoğan, 2015, s.38). 
Sorunun nedenlerine yönelik stratejileri uygulamak, kriz sürecinde bir zorunluluktur. Bir kriz yönetim takımı oluşturularak, krize yönelik çabalar başlatılmalı, stratejik iletişim planları geliştirilmeli ve takım sözcüsünü belirlemelidir. Krizi çözmeye yönelik değişiklikleri başlatacak yeni çalışmalar ve atılımlar başlatılmalıdır.

Kuruma karşı olumsuz hareketler gösterenler veya yanlış yönlendirilenler, kriz döneminde toplumu olumsuz etkileyebilmektedir. Medyayı kullanarak kamuoyunu doğru yönlendirmek mümkün olabilir. Etkileşim sürecinin doğru olarak yürütülemediği durumlarda, algılanan görüşler ve dedikodular, bilgi boşluklarını doldurabilir (Kadıbeşegil, 2003, s.55). Gerçeklerden uzak bilgilerin paylaşıldığı ortamlara yönelik önlemler alınmalı ve gerçek bilgi ortamlarının egemen olması sağlanmalıdır.

Kriz süreci doğru yöntemlerle yönetilirse; kurumsal sorunların ortaya çıkarılmasını, çevredeki değişimlere uyum gösterilmesini, stratejilerin yenileştirilmesini, rekabetteki üstünlüklerin geliştirilmesini, yeni becerilerin edinilmesini ve yönetim anlayışlarının sorgulanmasını sağlar (Tüz, Haşit, İpçioğlu, ve Süher, 2013, s.5). Olağan dönemlerde günlük etkinliklerin baskısıyla yeniliklere yeterince zaman bulamayan kuruluş, kriz dönemlerini; rekabet üstünlüğü sağlayacak yenilikleri oluşturmak, kurum yapısında yeni düzenlemeler yapmak ve çalışanların becerilerini artırmak için elverişli bir durum olarak görmelidir (Baltaş, 2002, s.26-27).

Özellikle yaşanılan pandemi dönemleri, küresel ölçüde bir kriz ortamı yaratmıştır. Pandemi nedeniyle oluşan krizin etkileri; yalnızca sağlık sektöründe değil, tüm sektörlerde görülmektedir.

Kontrol edilmesi güç bir süreç olan krizlerin elverişli durumlara dönüşümünde en önemli etken, insan kaynaklarıdır (Kurt ve Özkara, 2006, s.675). Krize yönelik hızlı ve akılcı kararlar verebilen liderler, krizi yönetmede ön plana çıkmaktadır. Üstün duygusal zekâlı bir lider, tüm çalışanların duygusal zekalarından oluşan kurumsal duygusal zekâyı ve motivasyonu geliştirebilir.

\section{Kurumsal Duygusal Zekâ}

Duyguların fark edilmesi ve yönetilmesi, öğrenilebilen bir beceri olan duygusal zekâ ile ilgilidir. Özdevecioğlu (2004)'na göre zekâ ve duygu- 
sal zekâ, birbirini tamamlayan özelliklere sahiptir. Duygu ve zekâ kavramlarının, başarıya yönelik etkileri sorgulanmaktadır. Özellikle iş yaşamında duyguların önemi fark edilmiştir. Başarıyı doğrudan etkileyen iki kavram olan, zekâ ve duygu arasındaki ilişkileri inceleyen araştırmaların bir sonucu olarak; duygusal zekâ kavramı geliştirilmiştir. Değişen çevresel koşullara uyum sağlayabilmek için, duyguları yönetebilme ve iletişim becerilerine gereksinim duyulur. Duyguları yönetebilme becerisi, iletişim başarısını sağlamaktadır. Ayrıca, duygusal zekâ düzeyi arttıkça, sorun çözme becerisi de artmaktadır. Çalışanların ve müşterilerin mutluluğunu artıran bir örgüt iklimine ulaşmak, işletme ortaklarının ve yöneticilerinin hedefi olmalıdır. Bu tür bir örgütsel iklimi oluşturabilmek için, duygusal zekâ becerileri ve iletişim becerileri gerekmektedir (Gül ve Güney, 2019, s.142).

Duygular yönetilemediğinde, akıl becerilerinin kullanılmasında ve yönetilmesinde sorunlar ortaya çıar (Atabek, 1999, s.11). Duygusal zekâ; kişisel olarak harekete geçme, aksiliklere rağmen yaşamı sürdürme, dürtüleri denetleyerek doyumu erteleme, duygusal durumu yönetme, sorunu düşünmeyi engelleyen nedenleri önleme, ümitli olma ve diğerlerini anlama, becerilerini kapsar (Aslan, 2009, s.36-37).

Wong ve Law (2002)'a göre, duygusal zekânın dört boyutu belirlenmiştir. Bunlar; öz duygularını fark edebilmek ve ifade edebilmek anlamındaki öz duygularını değerlendirebilmek, diğerlerinin duygularını algilayabilmek ve yorumlayabilmek anlamındaki diğerlerinin duygularını değerlendirebilmek, öz duygularını denetleyebilmek ve düzenleyebilmek anlamındaki duygularını düzenleyebilmek ve öz duygularını kullanabilmek ve yapıcı etkinliklere yönlendirebilmek anlamındaki duyguların kullanabilmektir.

Kurumların karşılaması gereken duygusal gereksinimler bulunmaktadır (Goleman, 2018, s.349). Kurumları diğerlerinden farklılaştıracak duygusal becerilerden en öncelikli olanlar; kendini tanıma, duygusal yönetim ve başarı motivasyonu olarak vurgulanmıştır. Kurumsal duygusal zekâ düzeyindeki artış, kriz ve stres sürecini yöneten liderin, başarısını ve motivasyonunu olumlu yönde etkileyebilir. 


\section{İnsan Kaynaklarının Motivasyonu}

Motivasyon, bir hedefe yönelik olarak istekli olmakla ilgilidir ve aynı zamanda duygusal zekânın önemli bir boyutudur. Çalışanların hedefe yönelik başarma beklentilerini artırmak gereklidir. Örneğin, iş arama sürecinde çalışma talebinde bulunulacak olan kuruluşa telefon edilmezse, bir işe sahip olmak da mümkün olmaz. Bu nedenle çalışanların her türlü gayreti gösterebilmeleri için, motivasyon düzeylerini yükseltmesi gerekir. Çalışanların motivasyon düzeyleri arttıkça, öğrenme becerileri de artar.

Motivasyon, değişimleri gerçekleştirebilecek hareket gücünü sağlamalıdır (Goleman, 2018, s.327). İç motivasyon ve dış motivasyon arasında farklar vardır. İç motivasyonda ödül; işin kendisidir, bir işi keyifle yapabilmektir. Dış motivasyonda ise ödül; kariyer, ücret, ün gibi dış kaynaklı bir ödüldür (Solmuş, 2004, s.152). İnsan kaynakları, en önemli üretim faktörüdür. Çalışanların duyguları, insan ilişkileri yaklaşımından itibaren fark edilmiş ve bilimsel incelemelere konu olmuştur.

Krizler, zorunlu olarak konfor alanından çıkılmasını ve sorunlarla mücadele edilmesini sağlar. Kriz süreçlerinde değişim motivasyonu; iç çevreden değil, dış çevreden başlamış olur. Liderler, insan kaynaklarının değişimini yönetecek kişilerdir.

\section{Liderlik Türleri ve Etkileri}

Lider, bir amaca yönelik olarak kendisini takip eden insanları etkiler ve isteklendirir. Lider, vizyon sahibi bir kişidir. Liderlikle ilgili üç teoriden biri olan Özellikler Teorisi, doğuştan gelen özelliklerin, bir liderin gelişmesinde en büyük etkiye neden olduğunu ileri sürmüştür. İkinci teori grubu olan Davranışsal Liderlik Teorileri; doğuştan gelen özelliklerin değil, liderin gösterdiği davranış biçiminin, liderliğin gelişiminde etkili olduğunu vurgulamıştır. Durumsal Liderlik Teorileri ise, bulunulan ortam ve koşullara göre farklı liderlik türlerinin uygulanması gerektiğini iddia eder.

Duygusal zekâsı yüksek olan lider; duyguları yönetebilen, çalışanları destekleyerek iş tatmini artışını sağlayabilen ve çalışanların başarısına olumlu katkılar sağlayabilen bir bireydir (Doğan ve Demiral, 2007, 
s.225). Liderlik türlerini ve etkilerini ayrı ayrı incelemek ve değerlendirmek gerekmektedir. Hizmetkâr, dönüştürücü, işlemci, karizmatik, koç, özgün, babacan liderlik türleri ile güç kullanımına göre liderlik türleri; bu makalede incelenmiştir. Liderlere duyulan gereksinim, özellikle kriz ve stres sürecinde artmaktadır.

Hizmetkâr Lider: Liderlik Türleri içerisinde olan hizmetkâr liderliğe göre, bir kişiyi yönlendiren temel davranış, insanlara hizmet etmektir. $\mathrm{Bu}$ nedenle bazı kişiler, insanlığa hizmet etme amacıyla lider olma kararını verirler (Bakan ve Doğan, 2013, s.42). Bir liderin örgüt içinde güçlü ilişkiler geliştirebilmesi için, tüm taraflar arasında tutarlı bir iş birliği eylemi olmalıdır. En etkili düzeyde çatışmaları çözüme kavuşturmak için, "ben" yerine "biz" düşüncesi benimsenmelidir (Jones, 2018, s.11). Hizmetkar lider; sorunlara veya durumlara geleneksel olarak tepki vermek yerine, proaktif bir yaklaşım sergileyebilen bir liderdir. Öngörü, hizmetkâr liderin zihnindeki benzersiz bakış açılarını görselleştirmeyi sağlar. Ayrıca öngörü, biz odaklı bir toplulukla birleştiğinde, en yenilikçi ve en değerli liderlik biçimlerini ortaya çıarır (Jones, 2018, s.15). Yeni bakış açıları kazanmak için, başkalarının farklı görüş ve düşüncelerini dinleyerek açık bir şekilde kucaklamak isteyen kişi, hizmetkâr liderdir. Bir kuruluşu ölçülemez bir performans düzeyine çıkaracak, benzersiz ve dönüştürücü bir bilgi birikimi; başkalarını dinleyerek kazanılabilir. Burada fark edilmesi gereken konu; başkalarının yeni bakış açılarını benimsemenin ve risk almanın, kurumlarda yaratıcı bir değişime ve en yenilikçi büyüme düzeyine yol açmasıdır.

Liderin gücü, hassasiyet ve hizmetten gelir. Hizmetkâr liderlik gerçekleşmediğinde, kuruluştaki biz düşüncesi yok olur ve kurum içinde güçlü bir topluluk duygusunun gelişme süreci ortadan kalkar (Jones, 2018, s.12-14) .Bu durum ise, insan kaynaklarının motivasyonunu azaltır.

Hizmetkâr lider, çalışanların başarısını ve liderliğini geliştirmeye odaklanır. Bu nedenle, kurumsal duygusal zekâyı ve insan kaynakları motivasyonunu olumlu yönde etkiler (Ürü, Çalışkan, Atan, ve Yozgat, 2013, s.64). Çalışanların yetkilerle güçlendirilmesi, kurumsal duygusal zekâyı geliştirecektir. Çünkü yetkilendirme, çalışanların olgunlaşmasını sağlar. Sassone (2014)'ye göre insanları geliştirmek, hizmetkâr liderin 
temel yaklaşımıdır. Ruhî gereksinimler; motivasyonun arttırılmasıyla ve cesaretlendirilmeyle, giderilebilir.

Hizmetkâr liderlik, yedi boyutlu bir modelle açıklanmıştır (Patterson, 2003, s.5-8). Buna göre, liderin çalışanları sevmesi, tevazu sahibi olması, uzun vadeli bakış açısıyla çalışanları yönlendirmesi, fedakâr olması, çalışanlara yetki ve sorumluluk vermesi, liderin güven vermesi, hizmetkâr olmasi; yedi önemli hizmetkâr lider özelliği olarak belirtilmiştir. Hizmetkâr liderlik, dönüştürücü liderlikle ilişkilidir.

Dönüş̧ürü̈cü Lider: Dönüştürücü lider, insan kaynaklarının en uygun düzeyde kullanılmasına ve çalışanların üstün özelliklerine odaklanmıştır. Böylece, kriz sürecinde kuruluşu farklılaştıran bir yönetim becerisi sergilenerek yararlar sağlanmış olur. Vizyon oluşturan dönüştürücü lider, vizyonun ve dönüşümün gerekliliğini diğerlerine benimsetir (Paksoy, 2002, s.197). Dönüşümcü liderlik, Burns (1978) aracılığıyla sistemleştirilmiştir. Takım çalışanlarının moralini, motivasyonunu ve performansını üstün düzeylere çıkarabilen dönüştürücü lider; değişimde ustadır. Adaleti, özgürlüğü ve eşitliği kullanan dönüştürücü lider; morali ve motivasyonu artırmayı amaçlar.

Dönüştürücü liderin davranışlarının, motivasyona etkileri olumlu ve yüksek düzeyde bulunmuştur (Akbolat ve Iş1k, 2013, s.35-50). Dönüştürücü liderliğin önemli özellikleri şunlardır (Scandura ve Williams, 2004, s.449-451): İnsanların sorunlarına yönelik yeni yöntemler sunar. Takipçilerinin iyimserliğini ve motivasyonunu yükseltir. İletişimi akılcıdır. İnsanları, oluşturulan vizyonun benimsenmesi için ikna eder. Sorgulayıcıdır, yeni düşünceleri ve sistemli düşünmeyi destekler. Dönüştürücü lider, bireysel gelişime yönelik öneriler üretir. Kendisini izleyenlerin motivasyonunu artırarak örgüt amaçlarını geliştirir.

Dönüştürücü lider, bir düzen oluşturarak ve adil olarak iç motivasyonu geliştirir (Kunhert ve Lewis, 1987, s. 650). İzleyicilerinin uzun dönemli hedeflerine önem vermelerini ve odaklanmaların ister (Sparks ve Schenk, 2001, s. 850). Hedef göstermek ve rehber olmak; dönüştürücü liderin esin kaynağı olmasını sağlar, çalışanları güçlendirir ve ekip ruhunu canlandırır (Celep, 2004, s. 77-78). Böylece, kriz sürecindeki stresin olumlu yönde yönetilmesine katkıda bulunur. 
Esinlendirici motivasyon, etkileyicilik, zihinsel uyarılma ve bireyselleştirilmiş ilgilenme; Chemers (2000)'e göre, dönüşümsel liderliğin klasik dört bileşenidir. Bunlardan biri olan esinlendirici motivasyon; liderin, kendisini izleyenlerin karşılaştıkları sorunlara yönelik olarak, destekleyici bir tutum içinde olmasıdır. Bu tutum, çalışanların işlerini daha kaliteli yapabilmelerini ve görevlerinin anlamını anlayabilmelerini sağlar. Dönüştürücü lider, esinlendirici motivasyon nedeniyle çalışanların ekip ruhuyla ve coşkulu olarak çalışabilmelerini sağlar. Diğer bir bileşen olan etkileyicilik ise, dönüştürücü liderin, izleyicilerine yönelik örnek davranış sergilemesidir. İzleyiciler, dönüştürücü liderin üstün etik ve kararlılık özelliklerine sahip olduğu algısına sahiptir. Gao ve Bai (2011)'ye göre, zihinsel uyarılma bileşeni; liderin, sorgulayıcı yeni yöntemlerle sorunlara yaklaşarak, yenilikçilik ve yaratıcllık yönünde izleyicilerini desteklemesidir. İzleyicilerin kendilerini sorgulaması, zihinsel uyarılma ile sağlanır. Bu sorgulama; inanç, değer yargıları ve varsayımları içerir. Bireyselleştirilmiş ilgilenme bileşeni; liderin, başkalarının sorunlarını anlayarak çözebilmesi ve izleyicileriyle bireysel olarak ilgilenerek gelişim sağlamasıdır.

Freshman ve Rubino (2002)'ya göre liderin duygusal zekâsı, dönüşüm sürecinde ön plana çıkar. Dönüştürücü liderin olumsuz duyguları azaltıcı bir rehber olabilme özelliği, çalışanlarda güven ve duygusal zekâ artışı sağlamaktadır. Srithongrung (2011)'a göre dönüştürücü lider, kendisinin ve çalışanların motivasyon ve performans düzeyini beklentilerin üstüne çıarır. İnsan kaynaklarının örgüte olan bağlılığının stratejik bir etkiyle artmasını sağlar. Çalışanların davranışlarındaki dönüşümü, iç etkenlerle gerçekleştirir.

Dönüştürücü lider, bir stratejik lider olarak davranır ve amaçlarda yeniliğe önem verir. Eraslan (2004)'a göre, dönüşümsel liderlik uygulamalarıyla çalışanların örgüt vizyonuna odaklanabilmeleri sağlanır. Ayrıca, katılımcı kararlar alınır ve değişime önem verilir. Görevler, ekip çalışmalarıyla yerine getirilir. Maddi olmayan ödüllendirmeler de kullanılır ve vizyona odaklanılır.

Dönüştürücü lider; sorunların oluşmasına karşı gerekli önlemleri planlar ve proaktif davranışlarda bulunur. Yaratıcıllı̆ı artırmaya yönelik örgütsel kültür değişimini hedefler. Çalışanlar, liderin verdiği vizyon ve motivasyonla, amaçlara daha kolay ulaşabilir. Dönüştürücü lider, 
ekiplerin gereksinimlerine odaklanır ve motivasyon kazandırır. Lider, çalışanların davranışlarını tek tek sorgulayarak, hangi konularda yardıma gereksinim duyulduğunu anlamaya çalışır. Odumeru ve Ifeanyi (2013)'ye göre dönüştürücü lider; çalışanların üretkenliğini artırmak için, sorgulayıcı düşünmeyi ve sorunlara yönelik karar verme becerisini geliştirmeye çalışır. Aydıntan (2009)'a göre dönüştürücü lider, kendisini izleyenlerin becerilerini fark edip geliştirerek; onların özgüvenini, motivasyonunu ve vizyona yönelik performansını artırır. Ayrıca, kriz ve stres sürecinde duygusal zekânın etkili bir şekilde kullanılmasını sağlar. Dönüştürücü liderlikle karşılaştırılan diğer bir liderlik türü, işlemci liderliktir.

İşlemci Lider: İşlemci lider, var olan düzeni korumayı hedefler. Bu nedenle, genellikle çalışanların yaratıcılık ve yenilikçilik özelliklerine odaklanmaz. Karşılaşılan sorunlarda çalışanların ilk adımı atmalarını beklemeden araya girip çözüm bulmaya çalışır (Güzel ve Akgündüz, 2011, s. 284). Eraslan (2004)'a göre, işlemci liderlikte geçmiş kararlara önem verilir. Merkez tarafından verilen kararlar ve görevler, her bir çalışan tarafından yerine getirilir. Srithongrung (2011)'a göre işlemci lider, diş etkenler ile çalışanların motivasyonunu yükseltmeyi hedefler. Odumeru ve Ifeanyi (2013)'ye göre işlemci liderin bir özelliği, mevcut sorunlara odaklanmasıdır. Diğer bir özelliği, örgüt kültürüne bağlı olmasıdır. Çalışanlara yönelik ödüllerle veya cezalarla, hedeflerin gerçekleştirilmesine odaklanır. Her bir çalışanın kendi gereksinimini karşılar ve böylece motivasyon sağlar. Ancak, başarı artışına yönelik karar alma süreci, streslidir. İşlemci lider, dış etkenlere yönelik olarak duygusal zekânın kullanımına yoğunlaşmıştır.

Karizmatik Lider: Küresel ölçekte bilinen bir liderlik türü olarak karizmatik liderlik, tarihî başarılara sahip politikacıları ve komutanları hatırlatmaktadır. Son derece kendine güvenli ve cesur kişiliğe sahip liderlerdir (Avcı, 2019, s. 155-156). Çoğunlukla kriz sürecinde kurtarıcı olarak düşünülen ve olağanüstü kişisel özellikleri olan liderlerdir. Motivasyon özellikleri de çok güçlüdür (Çelik ve Sünbül, 2008, s. 52). Karizmatik liderliğin yalnızca olumlu yönleriyle incelenmesi ve sorgulanmaması yanlış olur. Kılınç (2002)'a göre, hem kendisini, hem de izleyenleri- 
ni yıkıma sürükleyen karizmatik ülke liderleri olmuştur. Karizmatik liderlikle ilgili olumsuzluklar, genellikle liderliğin sonraki süreçlerinde yaşanmaktadır. Ayrıca karizmatik lidere olan sadakat, liderin olumsuz özelliklerinin önemsenmesini önlemektedir. Kriz ve stres sürecinde olumsuz özellikler gösterebilen karizmatik liderler, duygusal zekâ ve motivasyonu da olumsuz olarak etkileyebilir.

Koç Lider: Koçluk tarzı lider; örgüt performansını, çalışan bireylerin motivasyonunu, liderlikle ilgili gelişmeleri ve performansı yüksek kadroların oluşturulmasını sağlayan uygulamaları gerçekleştirir. Bireyin istek ve becerilerini, grup hedefleri ile kaynaştırır. Üretim kalitesini ve çalışanların sunduğu hizmetlerin kalitesini artırarak katkıda bulunur (Campbell ve Samiec, 2010, s. 58-62).

Bir yönetici, koçluk tarzı liderliği, genellikle doğru olmayan inançları nedeniyle başarıyla uygulayamaz. Koçluk tarzı liderliğin aşırı karışık olarak düşünülmesi, bu nedenlerden biridir. Oysa koç liderlerin, uzman koçluk bilgisine sahip olmaları gerekmez. Koç liderlik uygulamalarını yönetmek için aşırı zaman ayırmak gerektiğinin düşünülmesi ve öncelik verilmemesi ise, diğer bir nedendir. Koç liderlerin, takım üyelerine daha çok zaman ayırması, çalışanlarda kapasite artışına ve üretilen işlerin kalitesinde artışa yol açar (Campbell ve Samiec, 2010, s. 95). Koçluk tarzı lider; üretkenlik, motivasyon ve bağlılık artışına yönelik çabalar gösterir. Çalışanların en üstün olduğu özelliklerine odaklanır. Koç lider, örgüt içindeki takımlara, vizyonu gerçekleştirme motivasyonu verir.

Koç lider, çalışanlarının gelişiminde duyguların önemini ve etkilerini kavramıştır. Kendi duygularını fark eden ve çalışanların duygularının da farkında olduğunu kendilerine bildiren koç lider; öncelikle çalışanları dinler. Koç lider, çalışanın olası kapasitesini bilir. Kendisinden beklenti içinde olduğunu belirtir ve böylece çalışanı hareketlendirebilir. Bu ilgiyi fark eden çalışan ise, başarıya ulaşmak için motivasyon kazanır ve sorumluluğunun bilincine varır (Goleman, 2002, s. 71-72). Ekip çalışmaları ve liderlikte, güven duygusuna öncelik verilmelidir. Güven, odaklanma ve motivasyon için temel bir duygudur (Blanchard, 2007, s. 133). Bilgi düzeyini artıran ve kapasitesini daha çok kullanmaya başlayan bir çalışan, daha farklı beceriler edinme gereksinimi duyar ve bireysel değişim endişesini hisseder. Koç lider ise, çalışanın sorun çözme 
yöntemlerinde yenilikçi olabilmesi için farklı düşünebilme yollarını ortaya koyar. Lider, öğrenme sürecinde çalışanın cesaretini ve güvenini artırmalıdır. Değişim sürecinde gereksinimlerin fark edilmesini sağlayacak soruları ise, koç lider oluşturmalıdır (Blanchard, 2007, s. 255). Kriz ve stres sürecinde yenilikçi ve farklı yöntemleri uygulayan koç lider, duygusal zekâyı ve motivasyonu olumlu yönde etkileyebilir.

Otantik Lider: Başkalarına benzemeye çalışmamak, özgün davranışlar göstermek ve yalnızca kendisi olmak; George (2003)'a göre, otantik davranışlar gösteren bir birey veya liderin özellikleridir. Otantik liderin özellikleri, dört boyutta gruplandırılabilir (Walumbwa, Avolio, Gardner, Wernsing, ve Peterson, 2008, s. 96-97): Kendinin farkında olma, denk değerleme, özümsenen ahlâkî bakış açısı ve ilişkisel şeffaflık. Kendinin farkında olma, otantik liderin; başkaları tarafından nasıl değerlendirildiğinin, kuvvetli ve kuvvetsiz taraflarının, kendi isteklerinin, duygularının bilincinde olmasıdır. Denk değerleme boyutu; liderin karar alma öncesinde, sorunla ilişkili bilgiyi tarafsızca sorgulamasını belirtir. Sorunla ilgili farklı görüşlerin geliştirilmesini destekleyici davranışlarda bulunur. Özümsenen ahlâkî bakış açısı; kişisel değerlerle birlikte, birlikte yaşanılan toplum yoluyla da yönlendirilir. Otantik ilişkisel şeffaflık, demek istenilenin aynen söylenildiği bir ilişkidir. Hedefleri ve istekleri aktarabilen otantik lider, kendisi hakkındaki artı ve eksi özellikleri hakkında da, başkalarını bilgilendirir. Kriz ve stres sürecindeki bu tür bir liderlik yaklaşımı; insan kaynaklarını bilgilendirerek ve destekleyerek duygusal zekâyı geliştirir. Otantik liderin, iş dışı hayatla ilgili çalışanlara yönelik uygulamaları belirgin değildir. Buna karşılık babacan lider, çalışanların iş dışı yaşamıyla ilgilenir.

Babacan Lider: Babacan lider, çalışanların iş dışındaki hayatlarını geliştirme motivasyonuna sahip olmalarını beklemektedir. Çalışanların iş dişındaki hayatlarına yönelik önerilerde bulunan babacan lider, onların işe sadık olmasını beklemektedir. Ayrıca, liderin çalışanlarıyla ilişkilerinde duygular etkili olmaktadır. Babacan lider tarafından alınan kararlar, çalışanlar tarafından sorgulanmadan yerine getirilmelidir. Ancak sorgulama olmaması, kurumsal duygusal zekâyı ve insan kaynakları motivasyonunu olumsuz yönde etkiler. 
Her bir çalışan, çalıştığı örgütü, iş dışındaki hayatı gibi benimsemelidir. Toplulukçu bir yapıda olan Türkiye'de, çalışanların iş dışı hayatına yöneticilerin karışması, genellikle normal karşılanır (Gerçek, 2018, s. 111114).

Vizyoner Lider: Vizyon, geleceğin uzun vadeli görüntüsüdür. Vizyoner lider, örgütün geleceğiyle ilgili belirsizliği, gelecekle ilgili net hedeflerle azaltabilir. Değişimin artan hızına yönelik uyum sürecinde vizyonun paylaşılmasını sağlayan vizyoner liderin en önemli rolleri, Çelik (1997)'e göre bir yol örneğiyle açılanabilir: Öncelikle, izlenecek olan yolu görmek gerekir. Yolu görmek; gelecekteki hedefin ve hedefe ulaştıran en uygun stratejinin imgelenmesidir. Yolda yürümek; kararın uygulamaya geçirilmesidir, hedefe yönelik stratejiyi uygulamaya başlamaktır. Yol olmak; liderin kendi vizyonuyla yeni yolları açması ve izleyicilerini güvenle yolun sonundaki hedefe ulaştırmasıdır. Eğer vizyon önemini kaybederse, yeni stratejik yollar aranabilir. Vizyonun oluşturulmasında sezgiler de kullanılır. Vizyon sahibi insanlar, liderler; insan kaynaklarının motivasyonu ve duygusal zekâsını doğrudan etkileyebilir. Vizyona odaklanan bir diğer lider, ruhsal liderdir.

Ruhsal Lider: Ruhsal lider, insan kaynağının önemini farkeden ve şefkâtli davranan bir liderdir. İnsan kaynaklarını yetkilendirerek motivasyon artışı sağlar. Ruhsal lider, örgütteki çalışanları liderliğine ortak eder gibi, birlikte gerçekleştirilen bir liderlik tarzı sergiler (Akar, 2010, s. 55). Bireysel kahramanlığı değil, topluluğu cesaretlendiren ruhsal lider; kişisel kusurlarına direnir ve çözüm arar. Lider ve izleyicileri, yapılan işlerin sorumluluğunu beraber üstlendikleri için motivasyon artışı sağlanır (Korkut, 2012, s. 57). Kendisini ve çalışanlarını ruhsal olarak memnun eden ruhsal lider, Fry (2003)'a göre, tutum ve davranışlarıyla insanların özgüvenlerini artırmayı amaçlar. Çalışanların ruhsal ve manevî yönlerine odaklanarak harekete geçer.

Ruhsal lider; her bir çalışanın içsel motivasyonunu artırdığı gibi, çalışma arkadaşlarına yönelik motivasyon aşılayan davranışlar göstermelerini de sağlar. Ruhsal liderin amacı, motivasyona sahip öğrenen bir örgüt oluşturmaktır. Manevi kurtuluşu kapsayan ruhsal liderlik teorisinde kullanılan model, iç motivasyondur. Örgütsel bağlılığı, perfor- 
mansı ve verimliliği artıran ruhsal lider; yaşamın anlamının hissedilmesini, örgüt içinde paylaşılan vizyonla sağlar. Ayrıca, çalışanların kabul edildiği ve anlaşıldığı bir örgütsel kültürün oluşturulmasını sağlar. Kendi geçmişini saygıyla kabul ederek, çalışanlarla iyi ilişkiler kurar. Sahip olduğu manevi inançla kendisinin farkında olarak, adım adım gelişim süreci içinde olur.

Ruhsal liderin taşıdığı önemli nitelikler; Fry (2003)'a göre yaşamın anlamının daha iyi anlaşılmasını sağlar: Bu niteliklerden ilki olan vizyon, kararlılığın ve ümidin bir bileşimidir. Vizyon, geleceğin resmi olarak düşünülebilir. Diğer önemli bir nitelik olan çalışanlarını yetkilendirmesi ise; ruhsal lidere duyulan güveni ve çalışma motivasyonunu artırır. Ruhsal liderlik, dinî öğretilerle ilgili olabilir veya tümüyle dinî öğretilere karşı ilgisiz kalabilir. Sonuç olarak, ruhsal gereksinimler üzerinde düşünülmesi gerektiği bilinci, giderek daha çok önem kazanmaktadır. Kriz ve stres sürecinde çalışanların duygusal zekâlarını geliştiren ruhsal lider, insan kaynakları motivasyonun,u olumlu yönde etkilemektedir. Ruhsal lider ile karşılaştırıldığında; ümitli ve inançlı olmayı vurgulayarak çalışmanın manevî yönünü vurgulayan ruhsal lidere karşılık, yönetimde ahlâkı vurgulayan etik lider, söz konusudur.

Etik Lider: Etik davranışlara öncülük eden etik lider; tarafsızdır, hakkaniyete uygun kararlar verir ve kuralları olan bir insandır. Dosdoğru ve güvenilir olan etik lider; etik kurallara uyulup uyulmadığını kontrol ederek gerekli yaptırımları uygular ve etik konularında çalışanlarıyla sürekli iletişim halindedir. Etik liderin uygulamaları, örgütsel adaletin gerçekleştirilmesini kolaylaştırarak insan kaynakları motivasyonunu artırabilir.

Brown ve Trevino (2006)'ya göre, etik lider ile bazı liderlik türleri karşılaştırılabilir: Etik lider ile otantik lider karşılaştırıldığında; etik lider başkalarına, otantik lider ise öz farkındalığa odaklanmıştır. Dönüştürücü lider ile karşılaştııılırsa; standartların etik olmasını vurgulayan etik lidere karşıllk, zihinsel uyarılmayı ve vizyonu vurgulayan dönüştürücü lider vardır. 


\section{Sonuç}

İletişimin ve buna bağlı olarak değişimin hızlandığı süreçlerde, kriz ve stres ortamı insanları ruhsal yönden daha çok etkilemektedir. Duygusal zekânın daha çok konuşulduğu zamanlar, kriz ve stres süreçleridir. Bitmeyen kriz ortamlarında, çalışanların duyguları ve stres yönetimi öncelikle dikkate alınmalıdır. İnsan kaynakları, en önemli örgütsel kaynaktır. Motivasyon ise, duygusal zekânın temel bir bileşenidir. Liderlerin, insanın duygusal ve ruhsal özelliklerine önem vermesi gereklidir. Yönetim teorilerinden olan İnsan İlişkileri Yaklaşımı'ndan itibaren; insan faktörü, insanın duygusal yönü ve insan ilişkilerinin iş motivasyonuna etkileri, dikkate alınmaya başlanmıştır.

Bu makalede, literatür taramasiyla incelenen liderlik türlerinden dönüştürücü liderliğin ve özellikle ruhsal liderliğin; motivasyon ve duygusal zekâ üzerinde daha etkili oldukları söylenebilir. Her iki liderlik türü de, değişimi ve vizyonu vurgular. Ancak, ruhsal liderliğin bir farkı, değişimin ruhsal yönüne de önem vermesidir. Senge (1990)'e göre, çalışanların kendi performanslarını arttırmada süreklilik göstermeleri ve bunun için hayat boyunca öğrenmeye öncelik vermeleri; ruhsal liderin özellikleri arasındadır. Dönüştürücü ve ruhsal liderliğin ortak bir özelliği, bireysel ve kurumsal öğrenmedir. Sistemli bir kurumsal yapının oluşması için, kurumsal öğrenmeye odaklanmış olan ruhsal liderlik gerekmektedir. Dönüşüme öncelik veren bir kurumsal yapıda, kurumsal öğrenme gerçekleşmektedir. Bu dönüşümcü ortamın odaklandığı nitelikler ise; müşteri, sevgi, iç motivasyon, ekip çalışmaları ve yeniliktir. Baloğlu ve Karadağ (2009)'a göre, ruhsal ortam içinde öğrenme, en öncelikli amaç olarak görülür. İnsanların kendi iç dünyaları bulunmaktadır. İnsanların kendi iç dünyalarından ayrı olarak düşünülmeleri ve tüm yönleriyle değerlendirilmemeleri; insanın bütünlüğünün bozulması anlamında düşünülebilir. Ruhsal liderin etkin bir şekilde davranabilmesi için, çalışanların iç dünyalarına önem verilmelidir. Ertürk ve Dönmez (2017)'e göre, çalışanın görevine duyduğu inanç artışını sağlamak, ruhsal liderin bir görevidir. Salgın hastalık, kriz ve stres ortamlarında; ruhsal liderlik bu nedenlerle önem kazanmıştır.

Akbolat vd. (2013) tarafından yapılan bir araştırmada, dönüştürücü liderlik ve motivasyon arasındaki bağlantı; istatistikî olarak olumlu ve 
anlamlı bulunmuştur. Pandemi gibi belirsizliğin süreklilik gösterdiği dönemlerde, sağlıkla ilgili tüm çalışanların; yorgunlukla ve motivasyonla ilgili sorunlarında artış olmaktadır. Bundan dolayı dönüştürücü liderlik davranışları, özellikle sağlık sektöründe çalışanların motivasyonu üzerinde çok etkili olacaktır. Sağlık sektörü yöneticilerinin dönüştürücü liderlikle ilgili olarak kendilerini geliştirmeleri sonucunda çalışanlar, yaşanan değişimi uyumla karşılayabilir.

Bundan sonraki araştırmacıların, dönüştürücü liderliğin bir üst aşaması olarak ruhsal liderliği incelemeleri yararlı olabilir. Aydıntan (2009)'a göre, ruhsal zekânın dönüştürücü liderlik üzerine etkilerini araştıran uygulamalı çalışmalar vardır. Ruhsal zekâ yönünden üstün olmanın, dönüştürücü lider olma açısından da üstünlük sağlandığ1 bulunmuştur. Kendisini ve çalışanlarını hoşgörüyle affetmek, ruhsal zekânın bir özelliğidir. Ruhsal zekâ arttıkça; daha doğru, daha dürüst, daha çok sorumluluk sahibi, daha şefkatli, daha cesur, daha saygılı davranışlar artar.

Pandemi gibi yaygın hastalık dönemleri, insanların duygularını ve ruhsal durumunu etkilemektedir. Örneğin, salgın hastalık dönemlerinde insanlar daha çok yalnızlaşmakta ve stres yaşamaktadır. Bu nedenle gelecekteki araştırmacılar, özellikle pandemi gibi kriz dönemlerinde çalışanların içinde bulunduğu strese bir çözüm olarak, ruhsal liderliğin etkilerini araştırabilirler. 


\title{
EXTENDED ABSTRACT
}

\section{How Leadership Types Can Impact Corporate Emotional Intelligence and Human Resources Motivation in the Crisis and Stress Process?}

\author{
Ceylan Gazi Uçkun, Hasan Latif, Okan Şeneldir \\ Kocaeli University
}

Leaders experience great difficulties in crisis processes. Increasing environmental complexity triggers challenges. However, thanks to the motivation and emotional intelligence of the employees, the leadership power of the institutions increases. In this study, the relationships between leadership types and organizational emotional intelligence and human resources motivation were examined. In addition, how the crisis and stress process affects such relationships is discussed. It is an important study because it is one of the rare studies that focuses on corporate emotional intelligence and human resources motivation. This study, using the literature review method, was concluded with the view that the transformative leader and spiritual leader are more effective in the crisis and stress process.

The problem of the research is to determine the types of leadership that are more effective on human resources motivation and corporate emotional intelligence. Determining whether the effects of leadership types are different is the aim of the study. This study, which examines the effects of leadership in the crisis process, is important because it focuses on corporate emotional intelligence and human resources motivation.

An important factor that transforms crises into favorable situations is human resources (Kurt and Özkara, 2006). A leader who makes quick and wise decisions can successfully manage the crisis. Corporate emotional intelligence and motivation can be developed by leaders with superior emotional intelligence. When emotions are not managed, problems arise in the acquisition and execution of mental skills (Atabek, 1999). Maintaining life despite setbacks, managing emotional state, preventing reasons that prevent thinking about the problem, and being 
hopeful are some emotional intelligence skills (Aslan, 2009). Motivation for change starts from the external environment during the crisis period. The person who will manage the change of human resources is a leader.

A transformative leader creates a vision and convinces people of the necessity of transformation (Paksoy, 2002). Transformational leader's behaviors affect motivation positively and at a high level (Akbolat and Iş1k, 2013). It offers new methods for people's problems. It increases the optimism and motivation of the followers. It persuades people to adopt the created vision. Transformational leader produces suggestions for individual development. It improves organizational goals by increasing the motivation of its followers (Scandura and Williams, 2004). The transformational leader develops internal motivation by creating a system and acting fairly (Kunhert and Lewis, 1987). It wants to focus on strategic goals (Sparks and Schenk, 2001). As a guide to people, it strengthens them and revives the team spirit (Celep, 2004). Thus, it ensures the positive management of stress during the crisis.

Inspirational motivation is one of the four components of transformational leadership. The leader takes a supportive attitude towards the problems faced by his followers (Chemers, 2000). Due to inspiring motivation, it is possible to work with team spirit and enthusiasm. Another component, impressiveness, is that the transformative leader sets an example. With the mental stimulation component, the leader examines problems in new ways. The audience's self-questioning is provided by mental stimulation (Gao and Bai, 2011). The fourth component of transformational leadership is dealing with followers individually.

The leader's emotional intelligence comes to the fore in the transformation process (Freshman and Rubino, 2002). The transformative leader's ability to be a guide to reduce negative emotions provides employees with an increase in confidence and emotional intelligence. The transformational leader raises the motivation and performance level of himself and his employees above the expectations (Srithongrung, 2011). Transformational leadership practices enable employees to focus on the vision of the organization (Eraslan, 2004). In addition, participatory decisions are made and change is given importance. Tasks are accomplished through teamwork. Transformative leader who plans the necessary measures against the occurrence of problems; engages in proactive be- 
havior. The leader, who questions the behaviors of the employees one by one, makes an effort to understand which issues need help.

A spiritual leader is a leader who realizes the importance of human resources and acts compassionately. A leader who empowers human resources provides increased motivation and exhibits a leadership style performed together (Akar, 2010). Spiritual leader who encourages the community, not individual heroism; resists personal faults and seeks solutions. The goal of the spiritual leader is to create a motivated learning organization. The spiritual leader, who provides a shared vision within the organization, ensures that the meaning of life is felt. It also creates an organizational culture where employees are accepted and understood. A spiritual leader who respectfully acknowledges his or her own past establishes good relationships with employees. Being aware of himself with the spiritual belief he has, he is in the process of development step by step. The spiritual leader facilitates the comprehension of the meaning of life (Fry, 2003). A spiritual leader who empowers his employees increases his motivation to work.

As a result, transformative leadership and especially spiritual leadership; affect motivation and emotional intelligence more than other leadership types. Both types of leadership emphasize change and vision. However, one difference of spiritual leadership is that it also gives importance to the spiritual aspect of change.

\section{Kaynakça/References}

Akar, A. C. (2010). Ruhsal liderlik ve ruhsal liderliğin eğitim örgütlerinde uygulanabilirliği hakkında teorik bir çalışma. (Yayımlanmamış yüksek lisans tezi). Yeditepe Üniversitesi Sosyal Bilimler Enstitüsü, İstanbul.

Akbolat, M., Işık, O. ve Yılmaz, A. (2013). Dönüştürücü liderlik davranışının motivasyon ve duygusal bağlllı̆ga etkisi. Uluslararası İktisadi ve İdari Incelemeler Dergisi, 6(11), 35-50.

Aslan, Ş. (2009). Duygusal zekâ ve dönüştürücü, etkileşimci liderlik. Ankara: Nobel Yayınları.

Atabek, E. (1999). Bizim duygusal zekâmız. İstanbul: Altın Kitaplar Yayınevi.

Avcl, A. (2019). Örgütsel değişim ve örgüt yönetiminde karizmatik liderlik ve eleştirel bir bakış. Uluslararası Liderlik Çalışmaları Dergisi: Kuram ve Uygulama, 2(2), 148-157. 
Aydıntan, B. (2009). Ruhsal zekânın dönüştürücü liderlik üzerine etkisini araştıran uygulamalı bir çalışma. Atatürk Üniversitesi İktisadi ve İdari Bilimler Dergisi, 23(2), 257-274.

Bakan, İ. ve Doğan, İ. F. (2013). Liderlik. Ankara: Gazi Kitabevi Yayınları.

Baloğlu, N. ve Karadağ, E. (2009). Ruhsal liderlik üzerine teorik bir çözümleme. Kuram ve Uygulamada Eğitim Yönetimi, 15(58), 165-190.

Baltaş, Z. (2002). Krizde firsatları görmek: Yöneticiler için krizde yönetim el kitabı. İstanbul: Remzi Kitabevi.

Blanchard, K. (2007). Liderlikte çıtayı yükseltmek. İstanbul: Kaizen Yayınları.

Bono, J. E. ve Judge, T. A. (2004). Personality and transformational and transactional leadership: A meta-analysis. Journal of Applied Psychology, 89(5), 901-910.

Brown, M. E. ve Trevino, L. K. (2006). Ethical leadership: A review and future directions. Leadership Quarterly, 17, 595-616.

Burns, J. MG. (1978). Leadership. New York: Harper \& Row Publishers.

Campbell, S. ve Samiec, E. (2010). 5 boyutlu liderlik. İstanbul: Pegasus Yayınları.

Canöz, K. ve Öndoğan, A. G. (2015). Kriz yönetiminde dönüştürücü liderin rolü. Gümüşhane Üniversitesi İletişim Fakültesi Elektronik Dergisi, 3(1), 36-61.

Celep, C. (2004). Dönüşümsel liderlik. Ankara: Anı Yayıncılık.

Chemers, M. M. (2000). Leadership research and theory: A functional integration. Groups Dynamics: Theory, Research, and Practice, 4, 27-43.

Çelik, V. (1997). Eğitim yönetiminde vizyoner liderlik. Kuram ve Uygulamada Ĕ̆itim Yönetimi, 3(4), 465-474.

Çelik, C. ve Sünbül, Ö. (2008). Liderlik algılamalarında eğitim ve cinsiyet faktörü: Mersin ilinde bir alan araştırması. Süleyman Demirel Üniversitesi İktisadi ve İdari Bilimler Fakültesi Dergisi, 13(3), 49-66.

Doğan, S. ve Demiral, Ö. (2007). Kurumların başarısında duygusal zekanın rolü ve önemi. Celal Bayar Üniversitesi İ.I.B.F. Yönetim ve Ekonomi Dergisi, 14(1), 209-230.

Eraslan, L. (2004). Liderlikte post-modern bir paradigma: Dönüşümcü liderlik. Uluslararası İnsan Bilimleri Dergisi, 1(1), 1-32.

Ertürk, A. ve Dönmez, E. (2017). Ruhsal liderlik ve eğitimdeki yansımaları. MSKU Eğitim Fakültesi Dergisi, 4(1), 11-19.

Freshman, B. ve Rubino, L. (2002). Emotional intelligence: A core competency for health care administrators. Health Care Manager, 20(4), 1-9. 
Fry, L. W. (2003). Toward a theory of spiritual leadership. The Leadership Quarterly, 14, 693-727.

Gao, F. Y. ve Shanson, B. (2011). The effects of transformational leadership on organizational commitment of family employees in Chinese family business. 2011 International Conference on Economics, Trade and Development, IPEDR 7, 43-48.

George, B. (2003). Authentic leadership: Rediscovering the secrets to creating lasting value. San Francisco: Jossey-Bass Publishers.

Gerçek, M. (2018). Yöneticilerin babacan (paternalist) liderlik davranışlarının psikolojik sözleşme bağlamındaki beklentileri üzerindeki etkilerine yönelik bir çalışma. Eskişehir Osmangazi Üniversitesi İ̈BF Dergisi, 13(2), 101-118.

Goleman, D. (2002). İyi liderler. İstanbul: Varlık Yayınları.

Goleman, D. (2018). İşbaşında duygusal zekâ. (H. Balkara, Çev.). İstanbul: Varlık Yayınları. (Orijinal eserin yayın tarihi 1998).

Gül, E. ve Güney A. (2019). Duygusal zekâ ve iletişim becerileri arasındaki ilişki. Finans Ekonomi ve Sosyal Araştırmalar Dergisi, 4(2), 141-158.

Güzel, T. ve Akgündüz, Y. (2011). Liderlik davranışlarının orta düzey yöneticiler üzerindeki etkisi ve yöneticilerin tükenmişlik düzeyleri ile ilişkisi: Kuşadası otel işletmelerinde bir araştırma. ÇOMÜ Yönetim Bilimleri Dergisi, 9(2), 281-296.

Jones, P. R. (2018). Critical analysis of Robert K. Greenleaf's servant leadership: A journey into the nature of legitimate power and greatness. International Journal of Language and Literature, 6(1), 10-15.

Kadibeşegil, S. (2003). Halkla ilişkilere nereden başlamalı? İstanbul: MediaCat Yayınları.

Kılınç, T. (2002). Liderlik üzerine bir analiz. Hastane Dergisi (Hospital News), $3(15), 84-88$.

Korkut, A. (2012). Ruhsal liderliğe ilişkin kuramsal bir inceleme. (Yayımlanmamış yüksek lisans tezi). İnönü Üniversitesi Eğitim Bilimleri Enstitüsü, Malatya.

Kunhert, K. W. ve Lewis, P. (1987). Transactional and transformational leadership: A constructive, developmental analysis. Academy of Management Review, 12(4), 648-657.

Kurt, M. ve Özkara, B. (2006). Örgütler, metaforlar ve paradokslar: düzen ve değişim paradoksu temelinde askeri örgüt metaforuna ilişkin bir an- 
aliz. 14. Ulusal Yönetim ve Organizasyon Kongresi Bildiri Kitabı, 25-27 May1s, Erzurum, 675- 677.

Odumeru, J. A. ve Ifeanyi, G. O. (2013). Transformational vs. transactional leadership theories: Evidence in literature. IRMBR International Review of Management and Business Research, 2, 355-361.

Özdevecioğlu, M. (2004). Duygusal olaylar teorisi çerçevesinde pozitif ve negatif duygusallığın algılanan örgütsel adalet üzerindeki etkilerini belirlemeye yönelik bir araştırma. Ankara Üniversitesi SBF Dergisi, 59(3), 181-202.

Paksoy, M. (2002). Çalışma ortamında insan ve toplam kalite yönetimi. İstanbul: Çantay Kitabevi.

Patterson, K. (2003, Ağustos). Servant leadership: A theoretical model [PDF belgesi]. School of Leadership Studies Online Web site: 16 Mayıs 2020 tarihinde

https://www.regent.edu/acad/global/publications/sl proceedings/20 03/patterson servant leadership.pdf adresinden erişildi.

Sassone, V. (2014). Servant leadership [PDF belgesi]. Quality Texas Foundation Online Web site: 4 Ekim 2020 tarihinde https:/qualitytexas.org/wp-content/uploads/2014/11/Servant-Leadership.pdf adresinden erişildi.

Scandura, T. A. ve Williams, E. A. (2004). Mentoring and transformational leadership: The role of supervisory career mentoring. Journal of Vocational Behavior, 65(3), 448-468.

Senge, P. (1990). The fifth discipline. New York: Doubleday Publishing.

Solmuş, T. (2004). İş yaşamında duygular ve kişilerarası ilişkiler, psikoloji penceresinden insan kaynakları yönetimi. Ankara: Beta Basım Yayım.

Sparks, J.R. ve Schenk, J.A. (2001). Explaining the effects of transformational leadership: An investigation of the effects of higher-order motives in multilevel marketing organizations. Journal of Organizational Behavior, 22(8), 849-869.

Srithongrung, A. (2011). The causal relationships among transformational leadership, organizational commitment, and employee effectiveness. International Journal of Public Administration, 34(6), 376-388.

Tüz, M., Haşit, G., İpçioğlu, İ. ve Suher, İ. K. (2013). Haşit, G. (Der.) Kriz iletişimi ve yönetimi, Eskişehir: Anadolu Üniversitesi Yayını. 
Ürü, S. F. O., Çalişkan, S. C., Atan, Ö. ve Yozgat, U. (2013). Öğretim üyelerinin hizmetkâr liderlik davranışları ve ardılları üzerine bir araştırma. Ege Akademik Bakış Dergisi, 13(1), 63-82.

Walumbwa, F. O., Avolio, B. J., Gardner, W. L., Wernsing, T. S. ve Peterson, S. J. (2008). Authentic leadership: Development and validation of a theory-based measure. Journal of Management, 34(1), 89-126.

Wong, C. ve Law, K. (2002). The effects of leader and follower emotional intelligence on performance and attitude: An exploratory study. The Leadership Quarterly, 13(3), 243-274.

\section{Kaynakça Bilgisi / Citation Information}

Uçkun, G., Latif, H., ve Şeneldir, O. (2021). Kriz ve stres sürecinde liderlik türleri kurumsal duygusal zekâyı ve insan kaynakları motivasyonunu nasıl etkileyebilir? OPUS-Uluslararası Toplum Araştırmaları Dergisi, 17(38), 5819-5841. DOI:10.26466//opus.809051 